- RAM, REV. ADM. MACKENZIE, V. 11, N. 6, Edição Especial • SÃO PAULO, SP • NOV./DEZ. 2010 • ISSN 1678-6971 • Submissão: 3 jan. 2010. Aceitação: 27 ago. 2010. Sistema de avaliação: às cegas dupla (double blind review). UNIVERSIDADE PRESBITERIANA MACKENZIE. Walter Bataglia (Ed.), p. 6-30.

\title{
METADECISÃO NO MODELO DE GESTÃO TOYOTISTA
}

METADECISION IN THE TOYOTA MANAGEMENT MODEL

ALVAIR SILVEIRA TORRES JÚNIOR

Doutor em Comunicação Organizacional pelo Programa de Pós-Graduação em Comunicação da Universidade Metodista de São Paulo (Umesp-SP).

Professor da Faculdade de Economia, Administração e Contabilidade da Universidade de São Paulo (FEA-USP). Avenida Professor Luciano Gualberto, 908, sala C-12, Cidade Universitária São Paulo - SP - Brasil - CEP 05508-900 E-mail: alvair@usp.br 


\section{RESUMO}

O processo decisório no modelo de produção enxuta aparece como um fator pouco explorado na literatura. Os elementos que compõem o processo decisório aparecem marginalmente quando se discutem fatores como just-in-time, as parcerias com fornecedores, o desenvolvimento de produtos e a qualidade embutida no processo. O objetivo desta pesquisa é explorar como o processo decisório se apresenta no modelo de produção enxuta. Foram desenvolvidas entrevistas em profundidade com três ex-executivos do primeiro e médio escalão da subsidiária brasileira da Toyota Motor. Os entrevistados foram escolhidos intencionalmente e por oportunidade. Os resultados apresentam um conjunto de elementos do modelo de produção enxuta, denominados na literatura processos de solução de problemas, organizados em uma disposição própria, aqui reconhecida como uma metadecisão, a qual estrutura de forma peculiar o processo decisório do modelo Toyota. A contribuição deste trabalho é tornar explícita a estrutura de metadecisão do modelo de produção enxuta.

\section{PALAVRAS-CHAVE}

Tomada de decisão; Processo decisório; Modelo enxuto; Metadecisão; Toyotismo.

\section{ABSTRACT}

Decision-making in the lean production model appears as a factor largely unexplored in the literature. The elements that compound the decision-making process appear marginally when discussing other factors such as just-in-time, partnerships with suppliers, product development and quality built into the process. The objective of this research is to explore how the decision process is presented in the model of lean production. It was developed deep interviews with three former executives of the first echelon and middle echelon of the Brazilian subsidiary of Toyota Motor. The interviewed were intentionally chosen and by chance. 
The results show a set of elements of the lean production model, name in the literature as problem solving processes, arranged in a proper disposition, here recognized as a metadecision, which structure in a peculiar way the decision process of the Toyota's model. The contribution of this article is to make explicit the structure of the metadecision of the lean production model.

\section{KEYWORDS}

Making decision; Lean production system; Metadecision; Lean business; Toyotism.

\section{INTRODUÇÃO}

A literatura sobre processo decisório é caracterizada por uma multiplicidade de abordagens sobre os mais diferentes aspectos da natureza do fenômeno. Salvo classificações mais detalhadas que fogem ao nosso propósito, basicamente, tais abordagens se classificam em diferentes exposições de forma e conteúdo sobre o fenômeno decisão.

No que se refere ao conteúdo, há diferenças em termos de perspectivas do olhar sobre uma dada dimensão, partindo desde aqueles que se preocupam com as manifestações do ser humano na sociologia e psicologia da decisão, ao investigar as peculiaridades de nossa racionalidade, na busca por satisfação pessoal com as decisões ou, no âmago do ser, sobre decisões naturalísticas, instintivas e automáticas do dia a dia, até os mais racionalistas, que privilegiam as decisões no âmbito das organizações, estudando métodos quantitativos de otimização ou probabilísticos, que permitam mensurar as incertezas e complexidades do mundo real.

Em relação à forma, encontramos autores que, dentro de cada conteúdo, preocupam-se em estruturá-lo analiticamente, com maior ou menor riqueza de detalhes, estabelecendo o processo em suas fases e descrevendo-o ora com vistas a objetivos explicativos, ora tendo em vista ações prescritivas. Por outro lado, há os que formatam o conteúdo centrando mais na contextualização dos aspectos que envolvem o processo, expondo a estrutura ou o sistema que lhe dá sustentação, e espera por resultados.

Evidentemente, as combinações das diferentes perspectivas de forma e conteúdo, somadas às nuanças entre os extremos racionalista e intuitivo, organizacional e individual, processual e estrutural, explicativo e prescritivo, levam à 
complexidade do tema, porém, mais importante, levam à justificativa de estudar como algo tão variável e complexo se dá no âmbito do mundo real.

Dentre os clássicos que mais se aproximaram de um estudo abrangente da decisão e têm influenciado até hoje, com seus pressupostos, as pesquisas mais recentes, encontramos Herbert Simon (I955, I979) e o conceito da racionalidade limitada do homem organizacional. Se entendermos que todos aqueles que vivem em sociedade participam em cada instante de certo nível de organização, a contribuição de Simon foi fundamental para inaugurar estudos da decisão com perspectivas mais amplas e próximas da vida social e sua complexidade.

Uma objeção moderna, porém, é que aquele homem organizacional de racionalidade limitada, estudado por Simon, foi visto em um contexto de organizações com conteúdos burocráticos e formatos tayloristas-fordistas, em seus processos decisórios.

Desde então, a incorporação de tecnologia programável dos computadores e a inserção das necessidades de criação, proatividade ou empreendedorismo, fizeram com que autores modernos tivessem a necessidade de modelar o fenômeno organizacional com elementos mais adaptativos e flexíveis às distintas situações da realidade mais complexa e incerta.

Nesse contexto, o modelo de produção enxuta surge como uma inovação, e sua crescente adoção, como resposta à realidade cambiante (WOMACK; JONES, I998). Apresenta, também, certa regularidade no formato de suas manifestações, o que indica uma estabilidade na difusão dos conceitos e de sua estrutura básica. Torna-se uma oportunidade de investigação de como o fenômeno decisório aparece e dá suporte a essa estrutura emergente, estável e evolucionária (FUJIMOTO, I999). Em contrapartida, diversas nuanças do modelo burocrático, modernizado e atualizado, com adaptação e combinação de procedimentos, visando mantê-lo funcional, já são objeto tradicional de investigação, com a descrição de seus elementos do processo decisório estabelecida na literatura.

Assim, o objetivo deste trabalho é investigar aspectos do processo decisório utilizado no interior do modelo da produção enxuta, buscando obter maior conhecimento sobre as formas como se decide - metadecisão - na empresa símbolo desse modelo - a Toyota - e compará-los com os aspectos mais gerais da literatura tradicional sobre processo decisório, cujas prescrições foram tradicionalmente geradas e referenciadas em pressupostos do modelo burocrático moderno.

Para tanto, vamos objetivar a análise de como se processa a decisão na subsidiária brasileira da Toyota, por meio de entrevistas com ex-executivos do primeiro e médio escalão. 


\section{FUNDAMENTAÇÃO TEÓRICA}

A fundamentação do trabalho busca dois suportes teóricos: processo decisório e modelo enxuto, sem visar ser exaustivo, em função de nosso objetivo exploratório. Do lado da teoria da decisão, buscamos levantar em alguns autores mais citados na literatura quais prescrições mais gerais são recomendadas para a tomada de decisão e compará-las com os dados que obtivemos. Do lado do modelo enxuto, visamos identificar os elementos do sistema de produção Toyota que apresentem algum vínculo direto ou indireto com o fenômeno decisório, por meio do exame de autores consagrados na literatura sobre o assunto.

\subsection{TEORIA DA DECISÃO}

Mencionamos na introdução do artigo que Simon teve o mérito de chamar a atenção da academia, na década de I950, para a limitação das decisões nas organizações e cunhou, em contraponto à busca da decisão ótima, o conceito de decisão satisfatória. Simon destacou o fato de a administração trabalhar com um modelo simplificado da realidade, selecionando, dentre os inúmeros fatos e variáveis do mundo real, aqueles que julga ser relevantes para a situação particular a ser enfrentada.

O administrador empreende sua análise sob a perspectiva de um padrão satisfatório do mundo, formado por um número limitado de alternativas, cujo processo de escolha visa contemplar algo que represente uma solução satisfatória aos agentes ou adequadas à situação. Desde então, a influência dessas premissas de Simon é notória nos estudos mais recentes e que focam, em geral, dois grandes grupos de aspectos aqui adotados, segundo inspiração obtida no trabalho de Hoppe de Sousa (2006).

De um lado, aspectos que se ocupam com o processo decisório em si, suas fases e etapas. De outro, aqueles que se ocupam da estrutura que envolve o processo decisório, sua estrutura subjacente ou, como preferimos na adaptação da sociologia de Bourdieu (I982), a diferença entre estrutura estruturada, o processo já estabelecido em suas etapas, e a estrutura estruturante, aquela que fornece infraestrutura ao processo decisório ou, dito de outra forma, refere-se ao nível da metadecisão, respondendo às perguntas do tipo: quem deve decidir? Quem deve ser consultado? Quais etapas devem ser seguidas? Qual o tempo a ser despendido em cada etapa? Dentre outros aspectos que orbitam o processo decisório.

Não pretendemos fazer classificação de autores, mas apenas ressaltar como esses aspectos mais processuais e mais estruturais têm sido abordados na literatura sobre o tema. 
Clemen (I996) aborda a análise da decisão como um processo interativo no qual a percepção do tomador de decisão sobre os problemas pode mudar à medida que se avança ou se retorna às etapas de análise, as quais podem exigir vários ciclos para seu aprofundamento: identificar a situação e entender os objetivos, identificar alternativas, modelar o problema desenhando a estrutura da situação, registrar incertezas e preferências, escolher a melhor alternativa, proceder à análise de sensibilidade das consequências da escolha feita e implementar a escolha, caso não seja mais necessário aprofundar a investigação.

Keeney (I996) também estabelece etapas para análise do problema, porém enfatiza a geração de alternativas por meio de uma intensificação da interação do processo decisório, estabelecendo a recomendação de conhecer profundamente os valores de quem decide, indivíduo ou organização, e os objetivos, estabelecendo uma hierarquia dos objetivos diante daqueles valores. Assim, a transparência e o entendimento profundo de tais valores e seus objetivos são fundamentais no processo de levar à solução emergente, construindo proativamente situações desejadas.

Hammond, Keeney e Raiffa (I999) propõem oito passos, também na linha de uma postura proativa do analista, o qual deve observar e coletar todos os aspectos tangíveis e intangíveis da situação e tratá-los sequencialmente, segmentandoos nesses oito elementos, de forma sistemática: identificar o problema certo, definir o objetivo desejado, criar alternativas de curso de ação com imaginação, compreender as consequências de cada alternativa, equilibrar os objetivos concorrentes, estabelecendo os pontos de barganha entre eles, esclarecer as incertezas, ponderando sobre as probabilidades de resultados diversos, avaliar o nível de risco de cada alternativa e o nível de tolerância diante deles, examinar a interligação das decisões ao longo do tempo, avaliando o impacto sobre objetivos futuros daquilo que é decido hoje.

Mintzberg et al. (1976) enfatizam as decisões estratégicas e identificam, em seus estudos de campo, a presença de uma lógica que embasa os comportamentos dos atores na tomada de decisão, mesmo quando não há uma estruturação ou um processo explícito - ressaltam -, embora esse comportamento - destacam os autores - seja influenciado e alterado por fatores dinâmicos temporais que surgem durante o processo. Referem-se também a um nível de estrutura acima do processo decisório, a metadecisão, que visa estabelecer o planejamento do processo decisório e a alocação de recursos para dada decisão.

Wang (2000) acrescenta aos aspectos de planejamento e alocação de recursos outros fatores que viriam a compor essa estrutura, envolvendo o processo decisório: escolha do estilo de condução do processo decisório, escolha das pessoas participantes e da definição de seus papéis esperados, o equilíbrio entre formas de pensamento sistemático e intuitivo. 
Há influência da teoria de sistemas sobre os autores que estabelecem níveis de análise sobre o processo decisório, desde aqueles que se restringem ao primeiro nível na análise de uma decisão até aqueles que, como Russo e Schoemaker (2002) ou Kickert e Van Gigch (I979), dissertam sobre diversos fatores metadecisórios. Ambos representam os extremos do nível de adesão à perspectiva sistêmica ou estrutural, partindo desde o exemplo dos primeiros, com uma perspectiva mais calcada na experiência, até os últimos, representando uma postura de adoção de esquemas mais rigorosos de análise sistêmica, com uso da conceituação dos fatores de controle, ambientais e de retroalimentação.

Mais recentemente, abordagens que inserem a intuição e o papel das emoções na tomada de decisões têm ganhado corpo, à medida que a neurociência descobre as nuanças do funcionamento do cérebro humano (GLADWELL, 2005; DAMASIO, I999).

De forma geral, a distinção básica que queremos destacar nesses estudos clássicos sobre o fenômeno da decisão é que, de um lado, temos aqueles que, de alguma forma, enredam pela herança de Simon e definem fases do processo, etapas mais ou menos elaboradas na identificação do problema e no uso da inteligência para elaboração, exame e seleção das alternativas, e, do outro lado do espectro, aqueles que introduzem, sob influência das perspectivas estruturalistas e de sistemas, níveis em que se estabelecem relações entre os elementos do fenômeno da decisão, de forma tal a considerar aspectos como estilos, participações, relações humanas, liderança, intuição, entre outros, em níveis mais abrangentes do que o processo decisório em si.

De fato, o espectro de pesquisas é muito amplo para dar conta dos estudos de um fenômeno tão vasto e inserido na realidade organizacional do ser humano como a decisão. Quisemos aqui tão somente avaliar uma amostra do que é mais recorrente na literatura. Por outro lado, nessa grande amplitude, não encontramos menção ao fenômeno decisório no contexto do modelo organizacional emergente da produção enxuta. Tal modelo emergiu nas análises acadêmicas como mero sistema de produção, porém já evoluiu para ser considerado por alguns autores como um modelo organizacional mais amplo (WOMACK; JONES, I998; FUJIMOTO, I999; ROBERTS, 2004), aparelhado de tal forma que se difunde velozmente pelo mundo corporativo e atrai olhares pela forma como consegue se reproduzir sem muita nuança, isto é, decide-se o que fazer e como fazer para sua implantação claramente - apesar da dificuldade de executar -, por meio de elementos decisórios que fazem parte do modelo.

Examinamos, na sequência, as menções a tais elementos decisórios encontrados na literatura especializada no modelo enxuto. 


\subsection{ELEMENTOS DECISÓRIOS NO MODELO DE PRODUÇÃO ENXUTA}

O processo decisório aparece como um fator pouco explorado nos trabalhos de difusão do modelo de produção enxuta, no qual a Toyota é a empresa mundialmente reconhecida como pioneira, ao criar um sistema de produção voltado para a melhoria contínua dos indicadores de produtividade e qualidade.

Os elementos que fazem parte da estrutura de decisão são tratados secundariamente; aparecem marginalmente quando se discutem outros elementos, tais como just-in-time, as parcerias com fornecedores, o desenvolvimento de produtos e a qualidade embutida no processo, entre outros, mais reconhecidos por diferenciar o modelo toyotista do modelo tradicional da produção em massa.

Assim, mesmo em trabalhos mais recentes que reconhecem o modelo de produção enxuta como um modelo mais amplo, organizacional ou de negócio, elementos de claro vínculo com a estrutura de decisão surgem identificados mais à estrutura de elementos voltados à solução de problemas.

Liker (2004) enfatiza quatorze princípios por ele organizados sobre o modo Toyota de gerenciar; dentre os quais, quatro indiretamente se relacionam à forma de decidir na empresa: prioridade na tomada de decisões de longo prazo, com base em valores para a empresa, os clientes e a sociedade; a tarefa básica do gestor em obter dados da realidade, indo ao local e vendo com seus próprios olhos a situação; tomar decisões sem pressa e por consenso, considerando todas as opiniões, dentro de um processo de discussão chamado nemawashi, para, depois, implantar a decisão rapidamente; e, o quarto princípio, o aprendizado constante através da reflexão sobre os fatos e sua aplicação na resolução de problemas e melhoria constante.

Fujimoto (I999), ao analisar a evolução do sistema de manufatura na Toyota, interpreta-a por meio da formação de peculiares capacidades organizacionais em três níveis: rotinas de manufatura, rotinas de aprendizado e aprendizado evolucionário. Nelas, as decisões também aparecem implicitamente; em especial nas rotinas de aprendizado, consideradas como uma habilidade organizacional específica da Toyota em desempenhar ciclos de resolução de problemas de forma mais competitiva que seus concorrentes.

Dennis (2002, 2007), um ex-executivo da Toyota no Canadá, tem se aproximado mais da questão decisória com a publicação de sua experiência e a leitura da forma como a Toyota planeja e desdobra seus valores para os demais níveis da organização. Embora desdobramento de estratégias seja algo difundido no Ocidente por meio de práticas como o balanced scorecard, Dennis identifica no processo de planejamento estratégico da Toyota, conhecido como hoshin kanri - geren- 
ciamento ou desdobramento da política -, a peculiaridade de ele estar centrado em como utilizar as pessoas de toda a organização na seleção do que fazer para atingir a missão, privilegiando discussões que antecedem a definição da coisa certa a fazer, pela condução de um processo de perguntas às pessoas sobre o que impede a organização de atingir seus valores e os objetivos de negócio.

Registram-se as ações planejadas em todos os níveis hierárquicos em um formulário padrão de tamanho $\mathrm{A}_{3}$ e que condensa todo o pensamento e o controle das ações.

O trabalho do autor em difundir a prática do hoshin planning tem o mérito de chamar indiretamente a atenção para a faceta decisória no toyotismo, residente em um processo de participação e de perguntas sistemáticas para levantamento dos obstáculos e das oportunidades que contemplem os propósitos de toda a organização, embora o autor não esclareça questões sobre estilos, autoridade e poder, liderança, cujas respostas ajudam a compor uma estrutura de metadecisão.

Há, por exemplo, passagens no clássico livro de Taiichi Ohno (I988) que apresentam indícios sobre traços autoritários nos pioneiros da Toyota, cujo hábito de fazer perguntas aos subordinados, explorando problemas e rotinas, estava presente desde o início da empresa. Porém, diante de respostas insatisfatórias, incompletas ou óbvias, reagiam com rispidez. Tais passagens são da primeira metade do século XX, e cabe aqui relativizar isso, considerando, entretanto, que o estilo de condução das decisões deve ser investigado para compor aquilo que chamamos de metadecisão ou estrutura estruturante dos processos decisórios.

Por outro lado, Taiichi Ohno nos revela sutilmente a necessidade de ler a rotina decisória da Toyota em elementos menos abrangentes do que a estratégia e também analisar os alicerces operacionais e rotineiros do modelo. Ohno identifica, ao lado do just-in-time, o conceito de autonomação, automação com toque humano, como um dos pilares do sistema. O autor adverte para a diferença da autonomação em relação à simples automação, na medida em que a ênfase não é dada sobre a mera implantação do trabalho automático da máquina, mas, especificamente, em que o processo seja capaz de evitar os produtos defeituosos e a superprodução de forma autônoma.

Vinculado a esse conceito surge outro, conhecido como jidoka, a separação entre trabalho humano e trabalho da máquina, de forma tal que cada um possa ser executado independentemente do outro. Embora a leitura desses conceitos possa ser feita como descrição de elementos técnicos a serem considerados no desenho de tarefas eficientes e sem desperdícios, outra leitura possível, do lado da perspectiva decisória, emerge a partir de outra afirmação do próprio Ohno (I988, p. 28) sobre autonomação: "Dar autonomia à máquina e ao homem para parar a produção". 
Visto de outra forma, é o mesmo que dar autonomia ao nível operacional sobre a decisão do que é problema para interromper uma tarefa, dotando o sistema de inteligência para possibilitar o aprendizado ou, ainda, usando a expressão de Ohno (I988, p. 28): "Quando o problema é claramente compreendido, a melhoria é possível".

Aqui também parece residir elemento de uma estrutura decisória, revelando e selecionando os problemas com a participação dos níveis organizacionais e dando início ao processo decisório naturalmente, pela identificação de anormalidades ou do objetivo não alcançado satisfatoriamente.

Outro autor, Suzaki (I987), mais detalhista na descrição das técnicas, define jidoka ou autonomação como a capacidade autônoma de a máquina fazer um julgamento e decidir, extensivo também aos homens nos trabalhos manuais. Sem isso - completa -, a máquina pode mover-se por si só, mas não pode trabalhar para o homem. E o homem, por sua vez, não pode identificar a anormalidade e trabalhar para sua solução definitiva. Eu acrescentaria que ele não teria oportunidade de decidir.

Em síntese, a rotina estabelecida dentro do modelo de produção ou negócio da Toyota, disseminada no mundo sob princípios gerenciais conhecidos como lean thinking - mentalidade enxuta -, é reconhecida na combinação e repetição de cinco etapas resumidas por Womack e Jones (I998): especificar o que é valor para o cliente, alinhar na melhor sequência etapas que criam esse valor, realizar essas etapas sem interrupção, isto é, em fluxo, toda vez que alguém solicita o produto, puxando a produção, e realizar isso da forma mais eficaz, objetivando a perfeição, do ponto de vista de só executar atividades que gerem valor.

O que parece estar implícito nos conceitos descritos pelos autores, sugerindo a investigação ora proposta, é que esse pensamento lean ou toyotista inclui uma rotina sobre o que decidir, com base em seus valores, e como decidir, envolvendo não só as clássicas etapas do processo decisório vistas desde Simon, mas também uma estrutura que estabelece como esse processo decisório deve se guiar no contexto organizacional.

A exemplo do que Coriat (I994) muito bem analisou sobre a Toyota, ao cunhar a expressão de que os japoneses pensaram pelo avesso as mesmas questões que afligem a organização tradicional - no sentido de pensar em outra direção -, criando seu modelo, aqui também não se trata de levantar como fazer para analisar problemas e tomar as respectivas decisões, isso já está estabelecido dentro do arcabouço científico, e a Toyota o utiliza no ciclo PDCA, mas de investigar como a Toyota pratica isso em todos os níveis da organização, de verificar a sua estrutura estruturante da decisão e, ao que parece, como a empresa processa decisões de forma rotineira. 
Dito de outra forma, a literatura nos sugere que o toyotismo estabelece uma estrutura que torna natural a decisão com bases próximas ao científico, no sentido da retórica aristotélica, daquilo que é plausível diante de fatos, e não da verdade, pois verdade exige instrumentos distantes e inalcançáveis dentro da realidade organizacional e da vida corporativa (TORRES JR., 2000).

Assim, se autores como Bowen e Spear (1999), Womack e Jones (I998) foram competentes na leitura e descrição do conhecimento tácito do sistema Toyota de produção, sintetizando-o em princípios ou regras básicas que orientam todas as atividades, as conexões e os fluxos de produtos e serviços, estabelecendo desde o princípio sobre as conexões serem diretas e inequívocas entre clientes e fornecedores até sobre os fluxos obedecerem à regra da simplicidade, o fato é que há uma lacuna sobre como se decidem na organização os caminhos que realizam esses e outros princípios da mentalidade enxuta.

\section{MÉTODO}

Empreendemos uma pesquisa exploratória do tipo qualitativa (HAIR JR. et al., 2005), entrevistando três ex-executivos da subsidiária Toyota no Brasil. São brasileiros de ascendência japonesa e têm orgulho de ter trabalhado na Toyota em períodos entre doze e dezessete anos de trabalho. Atualmente, eles prestam consultoria na implantação do modelo enxuto em outras empresas, focados nas técnicas produtivas.

As entrevistas seguiram o método da entrevista em profundidade (GUBRIUM; HOLSTEIN, 2002), deixando que os executivos falassem todo o seu repertório a respeito de como as decisões eram tomadas na Toyota. O papel do pesquisador foi de tão somente, com frases curtas, incentivar o entrevistado a expor suas experiências com tomada de decisão. Cada entrevista durou de uma hora e meia a duas horas. Um dos entrevistados pertenceu ao nível estratégico, com treinamento na matriz japonesa; os dois outros ocuparam posições de gerência média, e um deles também estagiou no Japão.

A Toyota foi escolhida por representar a empresa referência na criação e no desenvolvimento do modelo enxuto. Os ex-executivos entrevistados trabalharam na subsidiária brasileira e, evidentemente, representaram uma oportunidade de pesquisa, uma amostra intencional e de oportunidade, adotada pela significância em investigar sem interferências da organização a experiência de ex-agentes do processo em análise.

Embora fosse significativo ter acesso direto à subsidiária e à matriz para corroborar certas afirmações, houve o cuidado metodológico de verificar que as 
afirmações dos três entrevistados coincidiram, inclusive com referência às experiências na planta japonesa, onde dois deles estiveram de um a dois anos em estágio de qualificação. Soma-se a isso a vantagem do processo de transferência do modelo organizacional desde o Japão guardar, implicitamente, ênfase no que os executivos da Toyota consideram como essencial.

A entrevista em profundidade, embora seja reconhecida pela característica particular de deixar à vontade o interlocutor para expressar espontaneamente $\mathrm{o}$ que lhe vem à mente sobre o assunto em pauta, deve ter por parte do pesquisador o cuidado de estimular, sem induzir, a profundidade das experiências em relação ao tema proposto.

Depois de uma introdução na qual se obtiveram dados de identificação do entrevistado e sua carreira na Toyota, alguns tópicos foram mencionados aleatoriamente, durante a entrevista, objetivando estimular a memória e o conhecimento do entrevistado:

Então, fale como as coisas eram decididas. Quem participava na estratégia, na gerência, na produção? Quem liderava? Como? Quem? O quê? Quando? Quanto tempo? Quem decidia? Quem era escolhido? Por quê? Entendo. Interessante. Explique mais sobre... Fale mais sobre isso. Conte uma história sobre isso. Havia consenso? Todos concordavam? E as discussões?

Vale notar que esses estímulos eram feitos de acordo com a ocasião, sem preocupação com ordem ou frequência. O pesquisador emitia a frase ou expressão facial na medida em que notava a necessidade de estimular a continuidade do pensamento e a manifestação do entrevistado. Assim, a expressão mais utilizada foi: "Continue falando como as coisas eram decididas". O silêncio ou pausa também foi usado para estimular.

As entrevistas foram realizadas em lugares escolhidos pelos entrevistados e eles foram avisados de que não poderia haver interrupção, o que foi satisfatoriamente cumprido, exceto por uma vez em que o entrevistado se retirou da sala.

Vale notar que os entrevistados foram contemporâneos na Toyota; dois deles com relação de chefe-subordinado entre si, porém não houve nenhuma divulgação prévia de opiniões ou do foco da pesquisa sobre decisão, tão somente avisouse que se tratava de uma pesquisa de como era o trabalho na Toyota.

As entrevistas, depois de gravadas, sofreram um processo de transcrição e foram analisadas pela técnica de análise de conteúdo temática categorial, com categoria definida a posteriori, que culminou na identificação dos aspectos de decisão no modelo Toyota descritos a seguir. 


\section{ANÁLISE dOS DADOS: ELEMENTOS DE TOMADA DE DECISÃO NO TOYOTISMO}

Uma opinião inicial e recorrente dos entrevistados foi sobre o início da implantação dos princípios do modelo enxuto nas organizações ser daquelas decisões tomadas necessariamente pelos gestores que decidem os rumos do negócio e não podem ser delegadas. Invariavelmente, envolve o chief executive officer (CEO) e deve ser antecedida de uma compreensão da abrangência e influência que essa decisão acarretará sobre o desenvolvimento de novos processos e mudanças na mentalidade das pessoas.

A análise das entrevistas nos permitiu inferir que essa mudança de mentalidade citada pelos entrevistados está profundamente ligada ao modo ou ao modelo padronizado de tratar as informações e tomar decisões praticado na Toyota. Foram identificados elementos que são recorrentes nas entrevistas, tais como planejamento $\mathrm{A}_{3}$, nemawashi, genchi genbutsu, gemba e hoshin kanri, de tal modo articulados e fortemente inseridos no dia a dia da organização que os entrevistados tampouco os faziam objeto de questionamento para considerar outro modo ou via de decisão.

Esse automatismo na forma de decidir que caracteriza um modelo de metadecisão pode ser ilustrado na declaração feita por um dos ex-executivos entrevistados, que, ao comentar sobre a adoção do modelo organizacional da Toyota por outras empresas, citou Womack e Jones (I998), enfatizando que esses autores consagraram, na difusão do modelo, a construção da mentalidade enxuta, prescrita como a busca por criar valor para o cliente, por meio de processos que façam esse valor fluir, evidenciando os desperdícios e buscando a perfeição. Essa consciência ou referência conceitual, porém, foi adquirida após a saída da Toyota, pois, no meio interno da empresa, não há a expressão da mentalidade enxuta nesses princípios; simplesmente, na fala de um do entrevistado: "Se faz as coisas como se espera que sejam feitas".

Em geral, os entrevistados se referiram às decisões vinculadas a implantações de projetos de produto ou processo em várias áreas da empresa, uma vez que todos trabalharam em vários setores organizacionais: produção, manutenção, engenharia, planejamento operacional, estratégia e recursos humanos.

Assim, com o cuidado de não se fazer referência a nenhum conceito pósToyota, o aspecto de como se decide foi estimulado na entrevista, buscando ressaltar a natureza do próprio processo de tomada de decisão em seu estado mais rotineiro. Foi mencionado por todos os entrevistados que, na Toyota, as decisões são tomadas dentro de um processo descrito na literatura como consenso 
(LIKER, 2004), envolvendo a discussão com atores de todos os setores envolvidos no tema a decidir, entretanto, sob estímulo para descrever esse processo, dois deles afirmaram que não se trata de um consenso como podemos entender no sentido mais amplo e pacífico, produto de um convencimento dos participantes, na verdade, muitas vezes, trata-se do resultado de um longo processo de discussão, aflorando discordâncias e fazendo negociações, até que haja um acordo pela aprovação da implementação de um plano de ação descrito em um formulário em formato A3 (297 x 420 milímetros).

\subsection{PLANEJAMENTO A3}

Nesse formulário, registram-se os planejamentos das ações, embutindo nele espaços que representam o passo a passo de uma forma peculiar de abordar os objetivos e problemas e tomar decisões a respeito deles. Daí os entrevistados se referirem muitas vezes ao elemento somente como $\mathrm{A}_{3}$ ou planejamento $\mathrm{A}_{3} \mathrm{ou}$, ainda, pensamento $\mathrm{A}_{3}$.

Nesse formulário (Figura I), deve estar inserido, obrigatoriamente na primeira metade da folha, do lado esquerdo, o histórico do problema ou da situação, a descrição da situação atual, a análise dos obstáculos, os limitadores e as oportunidades, a definição dos objetivos e as metas que se quer alcançar. Na segunda parte, inicia-se com o desenho da situação futura, seguindo o plano básico com ações ao longo do tempo para atingi-la e terminando com a definição de pontos de controle.

As descrições devem utilizar esquemas gráficos que representem as situações e facilitem o entendimento. Cada envolvido na decisão negocia individualmente com o responsável e, ao chegar ao acordo, assina esse documento, comprometendo-se a contribuir para o sucesso do plano.

Um dos entrevistados comentou que a negociação e a assinatura não significam unanimidade, mas a solução mais adequada diante das circunstâncias e das metas estabelecidas. Essa afirmação faz lembrar a decisão satisfatória de Simon (I979). Um entrevistado chamou esse processo de pensamento A3, em referência ao formulário nele usado que funciona como símbolo do processo (DENNIS, 2007), e todos os três também mencionaram o termo nemawashi para se referirem ao processo de negociação da decisão. 


\section{FIGURA I}

REPRESENTAÇÃO ESQUEMÁTICA DO FORMULÁRIO PLANEJAMENTO A3 FORNECIDA POR UM DOS ENTREVISTADOS

\begin{tabular}{|c|c|}
\hline \multicolumn{2}{|l|}{ Background } \\
\hline \multicolumn{2}{|c|}{$\begin{array}{l}\text { Contextos histórico e organizacional da situação } \\
\text { analisada }\end{array}$} \\
\hline \multicolumn{2}{|c|}{$\begin{array}{l}\text { Qual é a relação com os requisitos do negócio? } \\
\text { Qual é o problema? }\end{array}$} \\
\hline \multicolumn{2}{|l|}{ Situação atual } \\
\hline \multicolumn{2}{|l|}{ Onde estamos? } \\
\hline \multicolumn{2}{|c|}{ Como estamos? } \\
\hline \multicolumn{2}{|l|}{ Fatos e dados } \\
\hline \multicolumn{2}{|l|}{ Análise } \\
\hline \multicolumn{2}{|c|}{ Para detalhar a situação atual } \\
\hline \multicolumn{2}{|c|}{ Qual é a causa/raiz? } \\
\hline \multicolumn{2}{|c|}{ Quais são as restrições? } \\
\hline \multicolumn{2}{|l|}{ Meta/Objetivo } \\
\hline $\begin{array}{l}\text { Algo específico } \\
\text { situação atual }\end{array}$ & a ser alcançado para melhorar a \\
\hline
\end{tabular}

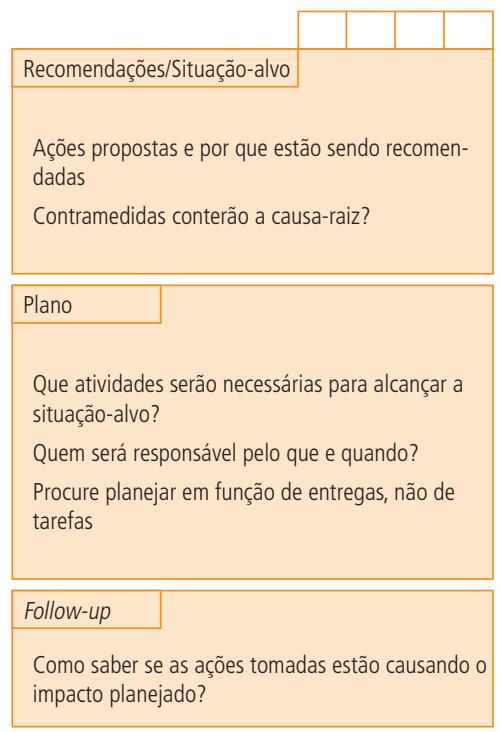

Fonte: Elaborada pelo autor.

\subsection{NEMAWASHI}

Nemawashi é o

[...] processo de conseguir aceitação e pré-aprovação de propostas através da avaliação da idéia - e depois do plano - com gestores e outros envolvidos para colher informações adicionais, reconhecer resistências antecipadamente e alinhar a mudança proposta a outras perspectivas e prioridades na organização (LEAN INSTITUTE BRASIL, 2007, p. 6I).

O termo em japonês - completa a definição - significa literalmente "preparar o solo para o plantio".

$\mathrm{Na}$ verdade, afirmou um dos entrevistados, a divergência é muito bem-vinda, e, durante o nemawashi, aquele que conduz a defesa de uma alternativa deve obrigatoriamente discutir com cada envolvido, procurando-o particularmente, ouvindo suas críticas e seus conselhos, e precisa ter habilidade para estabelecer barganhas - de ações, recursos e indicadores -, de forma a obter a aprovação 
daquela área organizacional, processo que, na literatura sobre modelo enxuto, também encontramos sob a denominação de catchball (DENNIS, 2007), cujo sentido como sinônimo de nemawashi consiste em uma troca entre os envolvidos, estabelecendo as metas e ações, sem abrir mão dos propósitos, mas considerando as dificuldades de cada agente na obtenção dos resultados, incluindo alternativas que levem em conta tais dificuldades.

O termo catchball, entretanto, vem sendo utilizado pela literatura de negócios com alcance limitado para representar tão somente a etapa de negociação entre os executivos, enquanto o termo nemawashi, nas entrevistas, sempre foi fortemente vinculado ao exaustivo processo de conversar com todos os envolvidos, desde o nível operacional até o estratégico. Busca-se ter compreensão ampla do objetivo ou problema, seu alcance e suas consequências, na medida em que alianças de esforços para atingir os objetivos também são estabelecidas, naquilo que se consagrou chamar de consenso japonês.

Estimula-se, nesse processo, segundo os entrevistados, o saber ouvir e o respeito às opiniões, sem abrir mão das conviç̧ões. Um exemplo citado foi o caso de redução do takt-time da linha de montagem, isto é, a necessidade de aumentar a produção, a qual exigiria, segundo um dos gestores afetados pela decisão, a necessidade de mão de obra adicional. Entretanto, a meta da organização era fazer sem contratação de ninguém. A solução foi uma barganha de que o processo seria implantado sem a contratação, porém respeitando os argumentos contrários. Acordaram-se uma avaliação e o monitoramento contínuo no conteúdo do trabalho, de tal sorte que, se não fossem eliminadas ou racionalizadas certas tarefas, haveria a liberação de hora extra e eventual contratação.

Aqui parece haver uma coincidência com o diagnóstico interativo de Clemen (I996) e a importância da fase de entender o problema e estabelecer negociações entre os objetivos do processo decisório. A diferença é que o toyotismo faz isso de forma a contemplar necessariamente todos os envolvidos no tema, e há um comportamento voltado para o debate exaustivo antes de se aprovar.

O executivo principal não é um sinalizador de opção, mas um crítico severo que estimula o debate. Ao chegarem para aprovação do principal executivo, todos os agentes já devem ter estabelecido acordo sobre o plano. Assim, apesar de as apresentações do formulário A3 para o executivo principal levarem entre dez a trinta minutos, as amplas discussões e barganhas já foram feitas, e todos envolvidos já assinaram.

Diferencia-se do método tradicional da decisão porque, embora o processo decisório seja semelhante, com etapas de levantamento de dados, problema, objetivos, criatividade e barganhas, nas empresas visitadas - em processo de implantação do modelo enxuto, mas ainda com formatos tradicionais da tomada 
de decisão - colhemos informalmente dados de que os bloqueios às implantações são, muitas vezes, severos, e as objeções sistemáticas, políticas, nas palavras dos consultados, destroem ou forçam certas tomadas de decisão que se desviam do foco.

Alguns observaram que, em certas reuniões, não se fala a verdade para evitar debates, confrontos ou não desagradar a certas personagens. Em oposição, na Toyota, os entrevistados salientaram que o "chefe" promove a discussão dos temas e a geração de alternativas para concorrer com o plano em debate. Na fala de um dos entrevistados: "precisa falar o que sente, o que acha. É um benefício para o líder do projeto. É uma traição, muito malvista, se não falar no momento da discussão do A3 e depois jogar contra".

Apurou-se que, no conteúdo das entrevistas, a busca do acordo, da aprovação no nemawashi, não deve ser confundida com uma forma de assembleísmo. Há uma busca por opiniões, um amplo processo de consulta, respeitando as diferentes perspectivas dentro da empresa. Entretanto, cumpre-se sempre o mesmo procedimento, seja uma decisão operacional ou estratégica, reportando-se sistematicamente ao que foi escrito no "formulário A3" (DENNIS, 2007, p. I2), cujo preenchimento é de responsabilidade daquele que deve conduzir o nemawashi e a tomada de decisão.

Ele é o responsável pela barganha e pela compensação entre contrários. Nesse ponto, sobressaiu a única divergência entre os entrevistados. Para um deles, aqui reside um lado obscuro da Toyota, a presença do autoritarismo e de jogos de poder interferindo no processo, com, muitas vezes, algumas decisões submetidas sem haver a devida discussão e negociação. Embora o entrevistado reitere sua opinião pela superioridade do processo, frisou que o mundo Toyota "não é o mundo perfeito que alguns querem mostrar".

Esse entrevistado, entretanto, pondera que, apesar dessas dificuldades, as influências políticas estão mais presentes na decisão convencional. Ele usa uma metáfora própria, comparando a decisão convencional com uma rede de pescadores que só apanha peixes grandes, aqueles que representam os donos do processo, os políticos, os gestores e os formadores de opinião, deixando de lado outros que não são considerados peixes importantes ou comerciais. Entretanto, continua: "Se a malha [da rede] for fina, poderemos arrastar tesouros para a superfície, peixes menores com pequenas pérolas”, que escapam às outras empresas.

Nesse sentido, a decisão na Toyota significa ter uma rede fina que traga à tona os verdadeiros acontecimentos do dia a dia, aquilo que o cliente sofre, as dificuldades do operador, eliminando da pauta o achismo ou a ideia de que isso não é objeto da decisão. 


\subsection{GENCHI GENBUTSU E GEMBA}

Essa busca por detalhes no dia a dia foi manifestada por todos os entrevistados, e ela tanto se refere a resolver um problema operacional quanto a saber como o consumidor utiliza o produto, como ele é atendido na concessionária, enfim, nas palavras dos entrevistados, antes de qualquer decisão, deve-se praticar o genchi genbutsu (obter os dados reais), indo ao gemba (local onde acontecem os fatos sobre os quais se quer decidir).

Na Toyota, essa prática consiste em compreender dada situação ou um problema pela observação direta da realidade. "Vá e veja com seus próprios olhos" deve ser a tônica para preceder qualquer discussão na tomada de decisão do modelo enxuto.

Exemplo citado em uma das entrevistas foi sobre o caso genérico de um grupo trabalhando em uma melhoria de processo qualquer na fábrica. O grupo deve observar o processo investigado, ir ao gemba, ao chão de fábrica, interagir com operadores, ouvir as áreas de apoio, visitar o local em horários e turnos diferentes. "Será que no turno da noite as condições são as mesmas do dia? Veja com seus olhos, faça o grupo coletar dados obtidos diretamente da realidade."

A decisão em outras empresas - prossegue o entrevistado - "se apoia em dados eletrônicos - nada contra a tecnologia -, em indicadores gerenciais que são filtrados, quando, na verdade, nos interessa a realidade como ela é". Aqui identificamos a preocupação em não tomar decisões tendo como referência leituras ou interpretações de um dado recorte da realidade. Interessa ao toyotismo tomar decisões levando em conta todos os aspectos do contexto, inclusive aspectos tácitos, percebidos no ambiente local.

Aproveitando a metáfora feita pelo entrevistado ao comparar a rede de pesca com o processo decisório, o toyotismo persegue a sistematização de um procedimento que não é novo, mas que seus gestores levam ao extremo: conhecer em detalhes a situação e o contexto, simbolicamente, que mar é aquele em que se lança a rede da decisão, quais espécies habitam, quais são seus hábitos, a época de reprodução, as leis da natureza, pois querer decidir só levando recortes à tona pode representar a perda da noção de que tais recortes de dados podem ser implausíveis diante de uma realidade imaginada, quando, na verdade, pode haver problemas de outra ordem no gemba (local onde acontecem os fatos sobre os quais se quer decidir).

Outra forma de interpretar a função dessa prática do genchi genbutsu é examiná-la à luz da literatura da neurociência, considerando que, na observação direta do problema e seu contexto, o cérebro identifica diversos sinais da situação e os processa independentemente de estarmos conscientes disso, memorizando-os e 
resgatando-os durante os processos decisórios. Estudos de neurocientistas (SANFEY et al., 2003; DIJKSTERHUIS et al., 2006) apontam que, enquanto a porção mais anterior, pré-frontal, do cérebro analisa evidências, estatísticas e projeções matemáticas ao considerar uma situação, o sistema límbico consulta rapidamente experiências anteriores semelhantes, aprendidas em exemplos e experiências diretos, muito além das instruções verbais, que formam aquilo que se convencionou chamar de intuição ou feeling.

\subsection{HOSHIN KANRI}

Por fim, outro aspecto mencionado pelo executivo que ocupou posição estratégica foi o processo de desdobramento da política, envolvendo um ciclo de decisões desde a cúpula da empresa até a definição de metas no nível operacional. Trata-se do hoshin kanri (DENNIS, 2002), em que os mesmos elementos enfatizados pelos entrevistados em situações de decisão ligadas à implantação de melhorias de processos ou projetos de lançamento de novos produtos seguem a mesma forma sistemática e rotineira no desdobramento da estratégia para cada ano, com participação de todos os níveis hierárquicos, em que cada um já conhece seu papel, o nível de detalhamento, quem é responsável e quando se deve fazer.

Assim, descreve o entrevistado que a estratégia é estabelecida pela alta direção, junto com o nível hierárquico imediatamente subordinado, seguindo esse movimento descendente até atingir a base operacional, havendo, em seguida, o movimento ascendente, na medida em que se processa o nemawashi, a negociação de planos e metas entre os níveis, sem abrir mão do propósito da empresa, mas considerando as dificuldades da base imediata, ouvindo os imediatamente subordinados, de forma que, quando o desdobramento retorna à cúpula, sabe-se que aquele plano é factível e foi negociado e compromissado em toda a organização.

No Quadro I, foi elaborada uma comparação entre as etapas clássicas do processo decisório e os elementos identificados nas entrevistas. Adotou-se Clemen (I996) como referência para as etapas tradicionais, sob a perspectiva de que essas etapas formam a estrutura estruturada também adotada na Toyota, porém complementadas pelos elementos estruturantes do modelo toyotista. Tais elementos moldam o comportamento dos envolvidos, prescrevendo as relações de consulta e participação que necessariamente devem ser registradas e evidenciadas no formulário padrão A3 (Figura I), constituindo-se sob a perspectiva estrutural da metadecisão aqui adotada, como elementos de uma estrutura estruturante da decisão, formadores de um processo evolutivo da decisão. 


\section{QUADRO I}

COMPARAÇÃO ENTRE OS MODELOS TRADICIONAL E TOYOTISTA

\begin{tabular}{|c|c|}
\hline $\begin{array}{c}\text { MODELO TRADICIONAL } \\
\text { ESTRUTURA ESTRUTURADA } \\
\text { AS ETAPAS DO PROCESSO DECISÓRIO }\end{array}$ & $\begin{array}{c}\text { MODELO ENXUTO } \\
\text { ESTRUTURA ESTRUTURADA + ESTRUTURANTE } \\
\text { COMPORTAMENTO DOS ENVOLVIDOS NO PROCESSO } \\
\text { DECISÓRIO }\end{array}$ \\
\hline $\begin{array}{l}\text { 1. Identifique a situação e entenda os } \\
\text { objetivos. }\end{array}$ & $\begin{array}{l}\Rightarrow \quad \text { Gemba/genchi genbutsu } \\
\Rightarrow \quad \text { Veja os fatos, entenda, obtenha dados da } \\
\text { realidade. }\end{array}$ \\
\hline 2. Identifique alternativas. & $\Rightarrow \begin{array}{l}\text { Nemawashi } \\
\text { Converse com todos os envolvidos. }\end{array}$ \\
\hline 3. Decomponha e modele o problema. & $\begin{array}{l}\text { Modele no formulário } \mathrm{A} 3 \text { os dados reais } \\
\Rightarrow \quad \text { obtidos nas fases anteriores e siga evoluindo } \\
\text { na discussão. }\end{array}$ \\
\hline 4. Escolha a melhor alternativa. & $\begin{array}{l}\text { Indique e receba sugestões de alternativas } \\
\text { durante nemawashi por meio de reuniões } \\
\text { recorrentes para apresentar evolução do } \\
\text { planejamento A3. }\end{array}$ \\
\hline $\begin{array}{l}\text { 5. Analise as consequências e, se } \\
\text { necessário, volte às etapas anteriores. }\end{array}$ & $\begin{array}{l}\text { Continue com nemawashi e genchi } \\
\text { genbutsu, submetendo alternativas às críticas } \\
\text { de opositores e aliados até obter consenso e } \\
\text { reunião final de assinatura do formulário A3. }\end{array}$ \\
\hline 6. Implemente a alternativa. & $\Rightarrow \begin{array}{l}\text { Hoshin kanri } \\
\text { Desdobre todas as ações com os envolvidos. }\end{array}$ \\
\hline
\end{tabular}

Fonte: Elaborado pelo autor.

\section{CONCLUSÃO}

Os resultados da pesquisa levam à conclusão de que os elementos, aqui reunidos, os quais estão dispersos na literatura sobre modelo enxuto de produção, em sua maioria sob a temática de processos de resolução de problemas, quando interpretados sob uma perspectiva integrada, formam uma estrutura de tomada de decisão sistemática e rotineira dentro da organização. Acredita-se que esse estudo exploratório sobre a perspectiva decisória no modelo enxuto venha a contribuir para a discussão da importância em se estabelecerem estruturas de decisão nas empresas. 
O modelo toyotista apresenta aspectos muito mais amplos do que métodos e ferramentas para soluções de problemas. As entrevistas demonstraram que os ex-executivos entendem essas ferramentas embutidas em um contexto de processo decisório padronizado, no qual os elementos e as etapas de decisão recomendados pelos autores da teoria da decisão também se acham presentes. O processo leva em conta objetivos, valores, coleta de dados, identificação de alternativas, que se diferenciam em relação ao modelo tradicional por apresentarem uma estrutura dentro da estrutura, isto é, uma estrutura metadecisória embutida no modelo organizacional enxuto, subjacente ao processo decisório, ou, como preferimos denominar, uma estrutura estruturante da decisão.

Muito embora os elementos aqui identificados também sejam considerados uma estrutura estruturada e construída pela empresa, tendo emergido de suas relações internas, da história, cultura organizacional, o fato que queremos destacar é a função estruturante acumulada por esses elementos, que os faz fortemente identificados com o conceito de metadecisão.

Cada elemento aqui comentado na análise dos dados é um duplo padrão, tanto de etapa como de comportamento no processo decisório. Definem-se em cada passo do processo decisório (estrutura estruturada) as relações e formas de como se deve construir o processo (estrutura estruturante). Logo, se o nemawashi é uma etapa a ser seguida (estrutura estruturada), ele também precisa ser feito considerando necessariamente relações de discussão e oposição com envolvidos e interessados, desde o nível operacional até o estratégico, em ambas as direções; e, se isso não for feito dessa forma, trazendo necessidade de outras etapas em forma de reuniões, visitas, coleta de mais informações (estrutura estruturante), o grupo não decidirá.

Quem decide, o nível de participação, o tempo dedicado, a profundidade de análise em cada etapa e a necessidade de ver o problema com os próprios olhos para entendê-lo plenamente são aspectos que estão estabelecidos na rotina e não deixam dúvidas aos seus colaboradores. Não obtivemos exemplos detalhados dessas definições, pois trabalhamos com a memória dos entrevistados, porém, em que pese essa limitação, conceitos descritos nas entrevistas, como formulário/planejamento $A_{3}$, genchi genbutsu/gemba, nemawashi/catchball e hoshin kanri, deixaram transparecer a evidência de esses elementos envolverem aspectos de desempenho de papéis, níveis hierárquicos, negociação, interação, estabelecidos em uma rotina com base em formulários padrão, os chamados A3.

Encontraram-se semelhanças com as etapas do processo decisório tradicional. Entretanto, o modelo tradicional carece de um aprofundamento na aplicação do conceito de metadecisão, em tornar as estruturas decisórias também estruturantes, evidentemente respeitando a peculiaridade de cada empresa e sua cultura. Não que elas não existam nas empresas, todavia, há uma predominância 
de várias formas de decidir vinculadas ao estilo do decisor, fazendo a aplicação da estrutura com comportamentos díspares. Entretanto, tal equilíbrio entre o consenso e a decisão com poucos, emblemas de uma e outra abordagem, deve ser discutido em outros trabalhos.

Nossa pesquisa valeu-se de informações do dia a dia de decisores da Toyota, mostrando que a padronização da estrutura de decisão possui amplo espectro em uma organização de sucesso, que já teve seu DNA mapeado em regras operacionais, mas poucos trabalhos para mapeá-lo em relação ao processo decisório.

Na busca do DNA da Toyota, os autores focaram regras do modelo enxuto para desempenho prático em seu dia a dia operacional, porém os dados coletados indicam que esse DNA só ficará completo se incorporar a natureza decisória embutida nele. Os valores organizacionais do modelo enxuto, por exemplo, interpretados em atributos de qualidade, valor agregado para o cliente, eliminação de desperdícios, entre outros encontrados na literatura, podem ser vistos como a determinação de valores fundamentais da organização, dentro daquilo que Keeney (I996) estabeleceu como o primeiro passo no modelo decisório em que os valores direcionam a solução.

A estrutura decisória no toyotismo é balizada pelas alternativas que mais se aproximam de tais valores. Ao final das entrevistas, ficou claro que aqueles exagentes de decisões sabiam exatamente como decidir. Os pilares do sistema de produção, como Ohno (I988) descreve os princípios do modelo Toyota, são uma expressão desses valores; o valor da qualidade, por exemplo. Toda a decisão, do estratégico ao operacional, deve de fato embutir a qualidade em sua raiz. Logo, se uma decisão tem as seguintes alternativas - I. segregar a não qualidade, 2. evidenciar a não qualidade e 3. parar a produção antes de fazer a não qualidade, qualquer agente no modelo toyotista não terá dúvidas de preferir decrescentemente de 3 a $\mathrm{I}$.

Evidentemente, aspectos de trade-off quanto ao custo e ao domínio técnico da solução aparecem em outros valores organizacionais, como baixo custo, automação amigável, simplicidade, relativizando soluções muito sofisticadas que poderiam emanar para sistemas prevencionistas automatizados de controle da qualidade.

Segundo a literatura e nossas visitas técnicas, boa parte da decisão de parar a linha de produção não é automatizada, mas está na mão do operário.

A estrutura subjacente ao processo decisório também é percebida quando os entrevistados enfatizaram o fato de o processo não considerar apenas uma ideia A ou B para ser implantada, seja por um aspecto de domínio hierárquico, seja por um dado especialista ter sido consultado. Na verdade, todo o processo exige a participação dos que estão direta ou indiretamente ligados às atividades, com sua efetiva colaboração e compreensão sendo condição necessária para a condução das mudanças. 
A etapa de entender o problema em todas as suas nuanças, ponto enfatizado pelos autores da teoria da decisão, recebe um reforço simbólico nessa estrutura estruturante do toyotismo por meio da prática chamada genchi genbutsu. Difundida e resumida pelos consultores norte-americanos nas exortações Go see, Ask Why and Show Respect, tal procedimento incorpora-se na prescrição comportamental de examinar presencialmente os fatos, o aspecto analítico de inquirir racionalmente o porquê de dada situação, com vistas a coletar dados e revelar as causas ou os fatores críticos do problema em questão, e o lado intuitivo e naturalístico da experimentação presente no contato direto com a ambientação do problema, seja ele no chão de fábrica, no atendimento ao cliente, na loja, no mercado como um todo.

Nessa linha explicativa, diversos trabalhos têm divulgado recentes descobertas neurocientíficas (GLADWELL, 2005; DAMASIO, I999; SANFEY et al., 2003; DIJKSTERHUIS et al., 2006) que respaldam a utilidade desse contato direto do tomador de decisão com a situação-problema, na medida em que o cérebro adquire inúmeras informações do ambiente, processa-as e as memoriza, resgatando-as automaticamente ao interagir com processos racionais e conscientes por ocasião da tomada de decisão. É aquilo que genericamente declaramos como intuição.

Por sua vez, esse movimento de interação que envolve essa estrutura estruturante da decisão ao lado do método de decisão é realizado por meio de ritos de negociação denominados nemawashi ou catchball, nos quais os gestores discutem com seus pares, subordinados e interessados em geral o desenvolvimento das ações, dos planos, dos impactos e das metas vinculadas.

Nesse processo, a estrutura revela um elemento fundamental de comunicação descendente e ascendente. Os entrevistados revelaram fatos e dados que ressaltam a recomendação de que todos saibam do que se está falando. Essa é a função do formulário coletado com um dos entrevistados e conhecido como planejamento $\mathrm{A}_{3}$ ou simplesmente $\mathrm{A}_{3}$ (Figura I).

Além de ser uma representação ou um resumo, a utilização do A3 representa uma linguagem comum que instrumentaliza o processo de nemawashi (negociação), no qual o grupo compartilha seu conhecimento sobre o processo atual, e, por fim, há um consenso sobre o que se quer mudar.

De forma geral, um ponto que sobressaiu na análise das entrevistas foi que esses elementos, do ponto de vista da tomada de decisão, configuram-se como algo muito mais amplo do que um processo de solução de problemas, como encontrado na maioria dos autores do modelo enxuto. O como decidir, conduzindo a criação, seleção e definição de alternativas em toda organização, torna-se evidente na fala dos ex-agentes. No lugar de enfatizar apenas a resposta à pergunta sobre o que fazer, escolhendo a melhor alternativa, dado um contexto específico, a estru- 
tura decisória no toyotismo galga um nível acima e se preocupa com o fluxo da tomada de decisão, com as respostas às perguntas sobre como fazer, quem deve participar, quem deve ser ouvido, quando ouvir e por quanto tempo.

Um dos entrevistados afirmou que considerava ser "durante as discussões", no fluir das informações e descrições, durante as interações dos agentes, que emergia o que realmente acontecia na realidade e se identificavam as oportunidades de melhoria ou soluções de problemas.

Ampliando essa perspectiva, uma contribuição que se pode inferir desse tipo de processo é buscar inserção dos clientes externos e/ou internos e seus respectivos ambientes também no fluxo decisório, trazendo-os para algo semelhante ao nemawashi e genchi genbutsu do modelo enxuto, de forma a interagir com os agentes em seus ambientes e criar alternativas que evitem os erros frequentes de desenhar planos futuros que não representem de fato avanços significativos na criação de valor.

Não restringir o processo decisório e sua estrutura subjacente apenas aos analistas profissionais e especialistas é uma mensagem extraída do modelo adotado no toyotismo. Aliás, essa é uma das armadilhas em que se incorre nas empresas. Grupos homogêneos, mesmo quando dentro de um processo isolado, podem refletir certo consenso corporativo, fechado em si, não representando uma decisão satisfatória dentro dos contextos mais complexos em que se dão as decisões. Para resgatar as decisões organizacionais satisfatórias descritas por Simon (I955) no contexto atual mais complexo, torna-se recomendável abrir o processo decisório aos fluxos do mercado e de todas as partes interessadas, às distintas ambientações e às respectivas discussões e aos debates.

\section{REFERÊNCIAS}

BOURDIEU, P. A economia das trocas simbólicas. São Paulo: Perspectiva, I982.

BOWEN, H. K.; SPEAR, S. Decoding the DNA of the Toyota Production System. Harvard Business Review, Boston, v. 77, n. 5, p. 97-I06, Sept./Oct., I999.

CLEMEN, R. T. Making hard decisions: an introduction to decision analysis. 2. ed. California: Duxbury Press, I996.

CORIAT, B. Pensando pelo avesso: o modelo japonês de trabalho e organização. Rio de Janeiro: UFRJ, I994.

DAMASIO, A. O mistério da consciência. São Paulo: Companhia das Letras, I999.

DENNIS, P. Lean production simplified. New York: Productivity Press, 2002.

Fazendo acontecer a coisa certa. São Paulo: Lean Institute Brasil, 2007.

DIJKSTERHUIS, A. et al. On making the right choice: the deliberation without attention effect. Science, Washington, v. 3II, n. 5763, p. 1005-1007, Feb. 2006. 
FUJIMOTO, T. The evolution of a manufacturing system at Toyota. New York: Oxford University Press, I999.

GLADWELL, M. Blink - A decisão num piscar de olhos. Rio de Janeiro: Rocco, 2005.

GUBRIUM, J. F.; HOLSTEIN, J. A. Handbook of interview research: context \& method. California: Sage, 2002.

HAIR, JR., J. F. et al. Essential of business research methods. New York: John Wiley \& Sons, 2005.

HAMMOND, J. S.; KEENEY, R. L.; RAIFFA, H. Decisões inteligentes: como avaliar e tomar a melhor decisão. Rio de Janeiro: Campus, I999.

KEENEY, R. L. Value-focused thinking. 2. ed. Cambridge, Massachusetts: Harvard University Press, 1996.

KICKERT, W. J. M.; VAN GIGCH, J. P. A metasystem approach to organizational decision-making. Management Science, Hanover, v. 25, n. I2, p. I2I7-I23I, I979.

LEAN INSTITUTE BRASIL. Léxico Lean: glossário ilustrado para praticantes do Pensamento Lean. São Paulo: Lean Institute Brasil, 2007.

LIKER, J. K. The Toyota Way. New York: McGraw Hill, 2004.

MINTZBERG, $\mathrm{H}$. et al. The structure of unstructured decision process. Administrative Science Quarterly, Ithaca, v. 2I, n. 2, p. 246-275, I976.

OHNO, T. Toyota production system: beyond large-scale production. New York: Productivity Press, I988.

ROBERTS, D. J. The modern firm. New York: Oxford University Press, 2004.

RUSSO, J. E.; SCHOEMAKER, P. J. H. Winning decisions-getting it right the first time. New York: Random House, 2002.

SANFEY, A. G. et al. The neural basis of economic decision-making in the Ultimatum Game. Science, Washington, v. 300, n. 5626, p. 1755-1758, 2003.

SIMON, H. A behavioral model of rational choice. Quarterly Journal of Economics, Cambridge, v. 69, n. I, p. 99-II8, I955.

. Rational decision making in business organizations. The American Economic Review, Pittsburg, v. 64, n. 4, p. 493-506, Sept. I979.

SOUSA, W. H. de. Decidindo como decidir - desenvolvimento de uma estrutura conceitual através de estudos de caso. 2006. Tese (Doutorado em Administração)-Faculdade de Economia, Administração e Contabilidade, Universidade de São Paulo, São Paulo, 2006.

SUZAKI, K. The new manufacturing challenge: techniques for continuous improvement. New York: The Free Press, I987.

TORRES JR., A. S. Retórica das ações. 2000. Tese (Doutorado em Comunicação Organizacional)Universidade Metodista de São Paulo, São Paulo, 2000.

WANG, Z. Meta-decision making: concepts and paradigm. Systemic Practice and Action Research, New York, v. I3, n. I, p. III-II5, 2000.

WOMACK, J.; JONES, D. A. Mentalidade enxuta nas empresas. Rio de Janeiro: Campus, I998. 